\title{
The Design of Interactive Digital Learning Resource in Geography of Middle School
}

\author{
Fengtao Guo \\ PhD., School of Geographic Sciences \\ East China Normal University \\ 500 Dongchuan Road, Shanghai 20024, China \\ email: fengtao.guo@foxmail.com \\ Yushan Duan*, corresponding author \\ School of Geographic Sciences \\ East China Normal University \\ 500 Dongchuan Road, Shanghai 200241, China \\ email: ysduan@126.com \\ Weiguo Zhou \\ School of Geographic Sciences \\ East China Normal University \\ 500 Dongchuan Road, Shanghai 200241, China \\ email: zhouweiguo21@126.com
}

\author{
Ziwen Liu \\ School of Geographic Sciences \\ East China Normal University \\ 500 Dongchuan Road Shanghai 200241, China \\ Email: tylx794800258@163.com \\ Joseph P. Stoltman \\ Department of Geography \\ Western Michigan University \\ Kalamazoo MI 49008- 5433 USA \\ email: joseph.stoltman@wmich.edu \\ Yeyang Yao \\ School of Geographic Sciences \\ East China Normal University \\ 500 Dongchuan Road, Shanghai 200241, China \\ email: yaozeyang90@126.com
}

\begin{abstract}
E-School bag and digital textbook was used in pilot school both China and abroad. Most of the digital textbook mainly focus on the digitization of text like an e-book, the presentation method of teaching contents in textbook not fully improve students' learning interest. The interesting and interactive subject contents are a critical restriction factor of implementing the geography E-School bag. The purpose of this research was to design multimedia interactive digital teaching resource in middle school geography for E-School bag pilot school. Through the literature, observe class and interview, in this paper, the authors propose design principles, procedure and mainly introduce one example for students in middle school by multimedia interactive and "life-story" strand.
\end{abstract}

Keywords-ICT, geography, middle school, teaching resource, E-School bag, Life-story

\section{INTRODUCTION}

With the rapid development of information and communication technology (ICT), ICT has infiltrated every aspect of life revolutionary; people's lifestyle and mode of production are undergoing profound changes, as well as the education. Moreover, students of today, called the "digital generation", are highly familiar with the digital environment have traits that differentiate them as learners from the generations that preceded them [1]. Recently, "E-Learning", "E-Schoolbag", "E-Bag" "digital textbook" and other updated terms become a pretty advanced topic all over the world. ESchoolbag applied in school had been an irreversible trend, and the E-Schoolbag would eventually bring a learning revolution [2]. Many countries around the word, such as Singapore, South Korea, Japan, are working to develop and implement E-bag or digital plan. The South Korean government decided to pursue the digital textbook development project on a national level, to reflect the huge changes in the education paradigm and to support the development of the creative talents who will lead society in the future [3]. Digital textbooks are defined as the digitalized forms of printed textbooks, which can be read, seen and listened through wired or wireless networks [4].

In China, the government formulated and implement the National Outline for Medium- and Long-term Plan for Education Reform and Development (2010-2020), it clearly states that Information technology have revolutionary effect on education development and need more attention [5]. E-bag programs were piloted in Shanghai, Beijing, Jiangsu, Zhejiang and other provinces and cities. For example, Education Department of Jiangsu province promulgate the document "Initiate the hundreds of E-learning pilot schools in basic education" in March 2012. Shanghai promote the development of "E-Schoolbag" and "Cloud computation" assisted instruction, and promote students to apply information technology for enriching study and research inside and outside the classroom [6]. From September 2012, beside the 10 pilot schools in Hongkou District and 40 pilot schools in Minhang District, Shanghai government requires each district must have E-bag pilot school.

The present research focus on the technology realization and whole function. Sung-Moo JUNG introduces the digital textbook development project and digital textbook platform and main functions [7]. Zhiting Zhu provides the E-school Bag system and functional modeling and individual learning environment as cloud; they think E-School bag can construct 
an all-round individual learning environment by resource, tools and service cloud. Mihye Kim developed a digital textbook standard format including an array of function and XML-based document formats to maximize the effectiveness of learning and facilitate the interoperability of digital textbook among different uses and service [8]. Cheolil Lim develops a userfriendly digital textbook platform interface through survey and follow-up evaluation [9].

However, the survey regarding geography middle school in Shanghai shows that one of the biggest problems is short of interesting and interactive teaching resource corresponding to digital textbook [10]. Most of digital textbooks development mainly focus on the digitization of text like an e-book, JeongIm Choi develop an interactive digital textbook based on the Universal Design for Learning(UDL) principles [11]. But there is rarely related study geography multimedia digital resource.

In China, the textbook in the middle school remain the format of textbook in the university. This is maybe not suitable for the laws of students' cognitive development. Moreover, the contents of geography textbook, especially region geography, is presented by geography elements, nearly each lesson introduces a place usually used in this order: location, climate, landscape, resources, culture, agriculture, industry, tertiary industry. Although it has beneficial effect on development of geography teaching, student can acquire kinds of geography information on the website including remote sensing image, electronic map, they maybe not interesting in geography contents like that. For this reason, Professor Lizhong $\mathrm{Yu}$ believes that we should reconsider which effects of the ICT on knowledge acquisition, spatial cognition and emotional education of students [12]. This paper mainly addresses improve students learning initiative, strength the self-directed learning and inquiry-learning.

The research question is how to design the geography digital resource for students in the middle school of China? 1) We would like to discuss the principles and steps design the digital resource. 2) The authors will give an interesting geography course example by using multi-media and interactive function.

\section{Design Principles for a Digital TeXtbook}

As expert of Multimedia instruction, around three top levelgoals in the design of multimedia instruction for the most meaningful learning, Richard E. Mayer put forward five principles for reducing extraneous processing, three principles for managing essential Processing, and two principles for fostering generative processing [13]. (See the table 1) The authors have all principles in mind when design geography digital resource. Some of them have significant effect, so they are used in the example following.
TABLE I. DESIGN PRINCIPLES OF MULTIMEDIA INSTRUCTION

\begin{tabular}{|c|c|c|c|}
\hline $\begin{array}{l}\text { Top level- } \\
\text { goal }\end{array}$ & $\begin{array}{c}\text { Reduce extraneous } \\
\text { processing }\end{array}$ & $\begin{array}{l}\text { Manage essential } \\
\text { processing }\end{array}$ & $\begin{array}{c}\text { Foster generative } \\
\text { processing }\end{array}$ \\
\hline $\begin{array}{l}\text { Design } \\
\text { principles }\end{array}$ & $\begin{array}{l}\text { 1.Coherence } \\
\text { principle } \\
\text { 2. Signaling } \\
\text { principle } \\
\text { 3.Redundancy } \\
\text { principle } \\
\text { 4.Spatial contiguity } \\
\text { principle } \\
\text { 5.Temporal } \\
\text { contiguity principle }\end{array}$ & $\begin{array}{l}\text { 1.Segmenting } \\
\text { principle } \\
\text { 2.Pre-training } \\
\text { principle } \\
\text { 3.Modality } \\
\text { principle }\end{array}$ & $\begin{array}{l}\text { 1.Personalization } \\
\text { principle } \\
\text { 2.Voice principle }\end{array}$ \\
\hline
\end{tabular}

\section{A. Multimedia principle}

People learn more deeply from words and graphics than from words alone, instruction containing words (such as spoken text or printed text) and graphics (such as illustrations, charts, photos, animation, or video) that is intended to foster learning [14]. Some of map and pictures in the textbook is old or not update, we use government websites, NASS and Google search the clear and fine graph, especially all kinds of maps, or web map. Meanwhile the beauty landscape and video clips from BBC, History or famous movies regarding geographic phenomenon, it not only helps student understand geography, but also is helpful for student's aesthetic interest. Moreover, such function of soft, such as enlarge/shrink/ drag, and Flash can increase the interaction between students and computer.

\section{B. The coherence principle}

People learn more deeply from a multimedia message when extraneous material is excluded rather than included. The rationale for the coherence principle is that people are better able to focus on the essential material if we eliminate extraneous material that could distract them [15]. For this reason, each page in our digital resource should be concise, the words should be less than the printed book. Too many words are harmful to students' eyes, and student wouldn't like to read many narrative words. If students are interesting in some content, they can click it for understand deeply.

\section{Signaling Principle}

People learn more deeply from a multimedia message when cues are added that highlight the organization of the essential material. The rationale for the signaling principle is that people will learn more efficiently if the lesson is designed to call their attention to the important material in the lesson and how it is organized. The author uses the icons, dynamic texts, bold texts, and textbox to highlight the key point, activity section, and tiles. Which can attract the students focus these contents.

\section{Personalization principle}

People learn more deeply when the words in a multimedia presentation are in conversational style rather than formal style. The rationale for this technique is that conversational style can prime a sense of social presence in the learner, which causes the learner to try harder to make sense in appropriate cognitive by engaging in processing, leading to learning outcomes that are better able to support problem-solving transfer. [16] The authors not only keep the formal geography concepts, also use vivid and living language. For example, we use "figure out answers" instead of "questions" for name of activities. 


\section{E. Voice principle}

People learn more deeply when the words in s multimedia message are spoken in a human voice rather than in a machine voice [17]. Based on this principle, we choose who have a good voice to read the content or make explanation on each page. Moreover, students can turn on or off the voice when using this digital resource.

\section{DESIGN METHODS AND STEPS FOR A GEOGRAPHY DIGITAL RESOURCE}

The work team has ten people in all including the professor, $\mathrm{PhD}$ and graduate student, undergraduate, middle school teacher for discussing and exchanging ideas. The authors use iebook software, of which is the first company integrated internet terminal, mobile phone termination, digital TV terminal into media system all over the world. The format of final production is exe, which address copyright issues, can't be copied like PPT or other software even in the process of making.

The method of designing digital geography textbooks is to design interesting and interactive teaching resources according to the characteristics of physical and mental development of digital natives. Especially on geography knowledge, concepts and principle, the authors consider the most basic cognitive rules that conform to children which is from easy to difficult, from the shallower to the deeper, from simple to complex, rather than teach scattered and little relevance knowledge points to students. Such as map, through a series of case study and activities, students can gradually realize the map and then use the map and finally draw the map, so this method suitably meets the students' cognitive laws. Second, the author uses the principle of multimedia and interaction to maximize the effectiveness of teaching. According to these methods, we design the geography digital resource. (see Fig. 1)

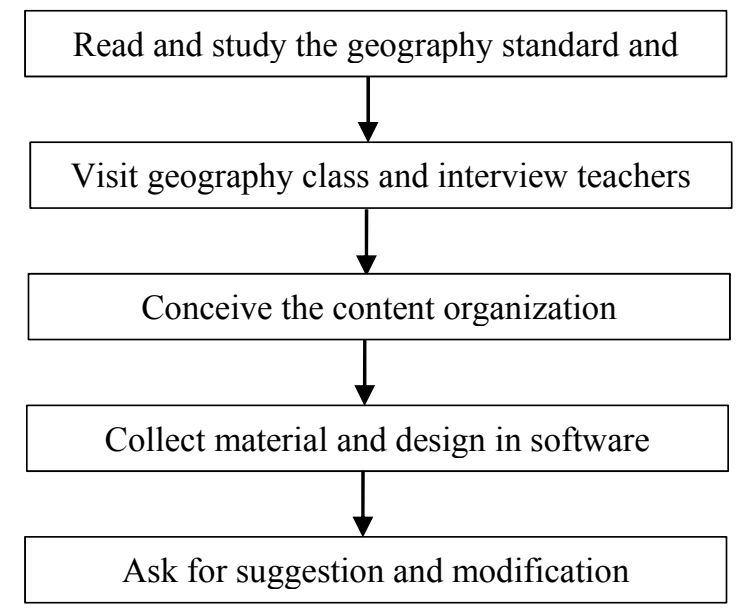

Fig. 1. Design methods for digital teaching resource

\section{A. Step 1 Read and study the geography standard and textbook}

In China, as an obligatory course in middle schools, geography can be studied as a stand-alone subject or as part of an integrated approach [18]. Geography in middle school emphasizes Regional Geography, including Chinese Geography, World Geography, and Local Geography.
Geography standards are guidance document for compiling textbooks, teaching, and evaluating teaching in China. Before 2000, nearly every school in China use the same geography textbook from People's Education Press. But now school or local educational administrative department can choose from 7 different publishers. For this reason, the author should read standard and all geography textbook to understand the requirement and summary the advantage.

\section{B. Step2 Visit geography class and interview teachers and students}

To know the existing teaching situation, the authors choose and investigate three diverse types of schools for each lesson. In every school, we all visit and listen the geography class to see how the geography content was be organized and taught to students. After the class, we also interview teacher with question like this: what are the key and difficulty points according your teaching experience? Which aspects do you think can be improve in the teaching procedures? The undergraduate student also talks with students. They ask do you like this lesson, which parts of content do you like best... The ideas are very valuable for us to develop digital teaching resource. In the process, we not only wrote the notes, but recorded the lesson and interview.

\section{Step 3 Conceive the organizational structure}

Structure and contents which is suitable for digital native is most important for designing digital resource. Content and organization structure not only based on the cognition level of middle school students, but also reflect the basic concepts of "learning geography which is useful to life" and "learning geography useful for lifelong development" in the standards. For example, students are familiar with cherry blossom in Japan. The authors use the cherry blossom as "strand" to design Lesson of Japan, all related geography knowledge and questions was represented by date of "the bloom of cherry blossoms" in different regional of Japan. In addition, the contents of geography learning resource should be organized with certain flexibility. For example, it's appropriate to arrange a certain amount of study, learning and reading content to meet the diverse needs of students. Finally, the authors write scripts that is the word text for design ideas.

\section{Step 4 Collect material and design in software}

After determining the structure of the contents, search and select the most appropriate contents is vital to development of digital resource. That material could be from textbook, courseware, official website, films; we just select the scientific, useful, and beautiful material. According to the principles of multimedia above, the authors begin to design multimedia in each page. In the process of development digital through iebook software, the authors keep continue discussing with the contents, collect relevant materials and revise them in time.

\section{E. Step 5 Ask for suggestions and modification}

When complete the product, the author seeks all the stokehold scientific advice from expert, professor, especially teacher and students in pilot school of digital teaching. 


\section{DEVELOPMENT OF GEOGRAPHY DIGITAL RESOURCE}

The work team has developed many courses [19]. Most of them are connected to real production and life, especially some geographical things, geographical phenomena and problems happened around the students. In this paper, we just list one example by strand of the "life-story".

We develop an introduction of first class for pupil in pilot school of Shanghai. The purpose of this course make pupil understands geography is around us, and it is helpful for our daily life. The title of this course is "One day of Shenshen" which introduces a pupil's day life. Shen is abbreviation of "Shanghai", so the authors named it "Shenshen", he is a middle school student in North junior school in Hongkou district of Shanghai. In the aspect of design, the author didn't set the page-flips effect according to the habit of reading printed book, and have beautiful home page and contents.

The content represents in a timed sequence, from breakfast, go to school by bus and 10 times periods to introduce the value of geography for produce and life. In this paper, we just introduce some pages.

\section{A. The source of breakfast}

\section{Sources of breakfast}

Think about

The ancients created many idioms just as follows: "Rice in the South, noodles in the North", "Pointed in the South, flat in the North", "Boats in the South, horses in the North", "Numerous in the South, simplex in the North", "Heavy industry in the South, light Industry in the North", "Short in the South, high in the North", "Flood in the South, drought in the North". Do you think these remarks make sense?

Design specification: This page mainly cultivates students' local feelings. The regional differences in geography form the consciousness of suiting measures to local conditions and cultivate the local feelings of side water and soil raises a side people. Through random examination of class students, it will be found that students who like to eat pasta mostly live in the north, so do their ancestors. This is because the northern climate and soil are suitable for growing wheat. And students who like to eat rice mostly grow in the south because the southern climate is suitable for rice. In addition, as shown in Fig. 2, Click Page set up multi click interactive exploration function. Students can click on the small maps such as Steamed Pork Dumplings, milk, watermelons, bananas and other food randomly and then the small map will enlarge and present a problem which can lead students to think. For example, after clicking on the first map there will be a problem, "do you know the difference between Beijing and Shanghai Steamed Pork Dumplings in the raw material?"; click on the milk, then "Do you know what makes Inner Mongolia a major base of milk in China?"; click on watermelon, then "Have you ever heard of soilless cultivation of watermelon? Do you know which areas of Shanghai have such agricultural production?". Through this kind of inquiry question, it can stimulate students to explore learning interests and enable students to understand different geography conditions and influence of science and technology on agricultural and sideline products. In addition, the author uses traditional idioms to expand students' thinking, expand students' understanding of Rice differences and deeply understand side water and soi. Rice s a side people.

\section{B. Chinese textbook}

Design specification: This page mainly uses the influence of traditional culture to train students' basic cultural accomplishment and sentiment. Curriculum standards in our country have always emphasized the enhancement of ideology and the overall inheritance of the fine traditional culture of China. Much ancient classical poetry contains abundant geographical information, and even by using the ability of geographical reasoning, people can infer the location of poetry. For example, the author quotes poems by poets named Li Bai and Bai Juyi, set up problems and inspire students to recognize the ability of preliminary geographical thinking. In addition, with the aid of contents two children argued in Shanghai Junior Chinese textbook, the textbook can not only stimulate students' interest in exploring and geographical imagination, but also train students' interdisciplinary ability and arouse students' heated discussion and research because of that thing which is difficult to test personally.

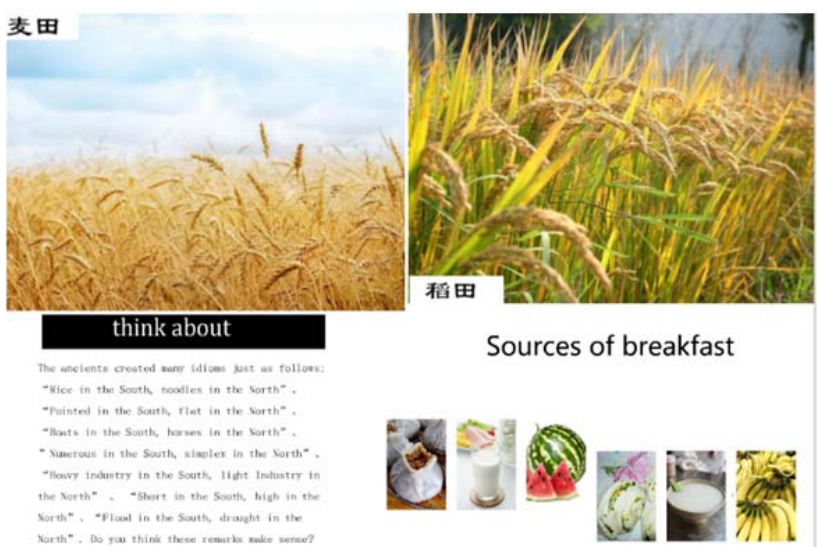

Fig. 2. The sources of breakfast

\section{DISCUSSION}

Digital teaching resources are not only limited to paper teaching materials, but also include other kinds of geography learning materials, such as workbooks and exercise books. According to the characteristics of middle school students' curiosity and cognitive characteristic, digital teaching materials not only provide text, but also make the key and difficult points visualize to be easier understood, thus satisfying the learning needs of different students. It also has the function of process management and online evaluation for each student's learning level, so as to help students learn more conveniently. Therefore, geography digital resource better reflects the ideas of development based on students, that is to make all students an all-around development as much as possible (entirety); take the differences between different students and unity of various aspects of students (otherness) into account; encourage them to develop positive and innovative mental states (initiative), thereby enabling them to conduct lifelong health development consistently (sustainability). 


\section{Chinese textbook}

Shenshen opens the Chinese textbook and found an ancient prose named Two Children Debate on the Sun. One child says: "I think the sun is close to people while just coming out, far from people at noon. " This is because the sun is big like the covering on the gig while just coming out, small just like the plate of food at noon, isn't this when the sun far is small and near seems big? But another child thinks the sun far from people while just coming out, close to people at noon. It's like stretching into hot water at noon while feels a little cold when the sun is just coming out. Isn't this exactly when the sun is near people feeling hot, far feeling cool?

At this point, Confucius also can't judge who is right and who is wrong. Can you help to explain?

\section{Interesting questions and answers}

An ancient poetry has said," When the flowers and sages in the plain are decaying,

Nowhere else but in the mountain temples is the peach blossoming. Is it because the peach blossoms around the temple are shy? Is that happening all over the country? Do you know the approximate location? Why does Li Bai think," The Yellow River comes from the sky and gallops to the sea without return."? Do you think it's scientific?

Of course, we still need to continue to explore the core concepts of geography and the core principles, what content should the geography textbook choose and how to optimize the organization better? What new theories will support my architecture? And so forth. Although there are some problems and shortcomings in the implementation of electronic textbooks in the process of development and research, the authors believe that digital teaching has become a trend in the future development. This is because our students have changed, and this change reflects the problems which need to be solved in our geography teaching. Change is always difficult, but we believe that the future is bright, because it is from the point of view of students. What we have done is to make learning better and make geography better!

\section{REFERENCES}

[1] Prensky, Mac. "Digital Natives, Digital Immigrants." On the horizon (2001).

[2] Zhu, Zhiting, and Xiaohua Yu. "The System of E-School Bag and Its Funcational Modeling ". e-EDUCATION RESEARCH, no. 04 (2011): 4(In Chinese)

[3] Jung, Sung-Moo, and Kwang-Bin Lim. "Leading Future Education: Development of Digital Textbooks in Korea." Paper presented at the 4th
World Teachers' Day in Thailand and 12th UNESCO-APEID International Conference Quality Innovations for Teaching and Learning, Bangkok, Thailand, 2009.

[4] KERIS. "Special Issue: Digital Textbook Leading Future Education." edited by Korea Education and Research Information Rervice, 1-15, 2007.

[5] China, Ministry of Education of the People's Republic of. " National Outline for Medium- and Long-Term Plan for Education Reform and Development (2010-2020)." edited by Ministry of Education of the People's Republic of China. Beijing, 2010. (In Chinese)

[6] Committee, Shanghai Municipal Education. "Shanghai Outline for Medium- and Long-Term Plan for Education Reform and Development (2010-2020).", edited by Shanghai Municipal Education Committee. Shanghai, 2010. (In Chinese)

[7] Jung, Sung-Moo, and Kwang-Bin Lim. "Leading Future Education: Development of Digital Textbooks in Korea." Paper presented at the 4th World Teachers' Day in Thailand and 12th UNESCO-APEID International Conference Quality Innovations for Teaching and Learning, Bangkok, Thailand, 2009.

[8] Kim, Mihye, Kwan-Hee Yoo, Chan Park, and Jae-Soo Yoo. "Development of a Digital Textbook Standard Format Based on Xml." In Advances in Computer Science and Information Technology, 363-77: Springer, 2010.

[9] Lim, Cheolil, Hae-Deok Song, and Yekyung Lee. "Improving the Usability of the User Interface for a Digital Textbook Platform for Elementary-School Students." Educational Technology Research and Development 60, no. 1 (2012): 159-73.

[10] Guo, Fengtao, and Yushan Duan. "A Q-Methodology Comparative Study of the Geography Teachers' Perception of E-School Bag in Shanghai." E-education Research, no. 8 (2015): 7. (In Chinese)

[11] Lim, Cheolil, Hae-Deok Song, and Yekyung Lee. "Improving the Usability of the User Interface for a Digital Textbook Platform for Elementary-School Students." Educational Technology Research and Development 60, no. 1 (2012): 159-73.

[12] Yu, Lizhong. "Reflections on Geography Education Refrom in Middle School." Geography Teaching, no. 5 (2012): 4. (In Chinese)

[13] Mayer, Richard E."Research-Based Principles for Designing Multimedia Instruction." Acknowledgments and Dedication 59 (2014)

[14] Mayer, Richard E. "Multimedia Learning." Psychology of learning and motivation 41 (2002): 85-139.

[15] Mayer, Richard E."Research-Based Principles for Designing Multimedia Instruction." Acknowledgments and Dedication 59 (2014)

[16] Mayer, Richard E, Sherry Fennell, Lindsay Farmer, and Julie Campbell. "A Personalization Effect in Multimedia Learning: Students Learn Better When Words Are in Conversational Style Rather Than Formal Style." Journal of Educational Psychology 96, no. 2 (2004): 389.

[17] Mayer, Richard E, Kristina Sobko, and Patricia D Mautone. "Social Cues in Multimedia Learning: Role of Speaker's Voice." Journal of Educational Psychology 95, no. 2 (2003): 419.

[18] Guo, F. T., J. P. Stoltman, Y. S. Duan, and T. Bourke. "A Comparison of Content Standards Documents for Geographical Tuition in China and the United States." [In English]. Mitteilungen Der Osterreichischen Geographischen Gesellschaft 158 (2016): 289-308.

[19] Guo, Fengtao. "The Education Value of Geography in Middle School." East China Normal University, 2015. (In Chinese) 